\title{
Cervical Cancer Risk Factors Association in Patients at the Gynecologic-Oncology Clinic of Dr. Soetomo Hospital Surabaya
}

\author{
Aisyiah Rahmi Putri ${ }^{1}$, Siti Khaerunnisa ${ }^{2}$, Indra Yuliati ${ }^{3}$ \\ ${ }^{1}$ Faculty of Medicine, Airlangga University, Surabaya, Indonesia. \\ 2 Department of Medical Biochemistry, Faculty of Medicine, Airlangga University, Surabaya, Indonesia \\ ${ }^{3}$ Department of Obstetrics and Gynecology, Dr. Soetomo Hospital, Surabaya, Indonesia
}

\section{ARTICLE INFO}

Received : 26 December 2018

Reviewed : 25 January 2019

Accepted : 20 November 2019

Keywords:

cancer, cervical cancer, parity, birth control pills, smoking

\author{
A BSTRACT
}

Background: Cervical cancer ranks fourth of all cancers in women worldwide and linked to human papillomavirus (HPV) infection. Despite the evidence of methods for cervical cancer prevention, such as pap smear test and HPV vaccination, most of the women remain unscreened and never get HPV vaccination. Most cervical cancer cases are not diagnosed early enough, leading to poor outcomes. This study aims to examine the association of risk factors with cervical cancer incidence in Dr. Soetomo Hospital Surabaya and also records the patients' knowledge of cervical cancer preventions, history of HPV vaccination, and pap smear screening test.

\begin{abstract}
Methods: This is a case-control study. Questionnaires were given to 60 newly diagnosed cervical cancer patients and 60 non-cervical cancer patients at The Gynecologic-Oncology Clinic of Dr. Soetomo Hospital Surabaya in the period of March 2016 until August 2016. The analysis was made using bivariate and multivariate logistic regression analysis.

Results: The bivariate logistic regression analysis confirmed that parity more than two times $(p=0.001)$, history of birth control pills consumption more than 10 years $(p=0.04)$, passive smoking $(p=0.001)$ and not knowing that cervical cancer can be prevented $(p=0.001)$ were significantly associated to the incidence of cervical cancer. The multivariate logistic regression analysis confirmed that not knowing that cervical cancer can be prevented ( $O R=6.85$ ), the history of passive smoking $(\mathrm{OR}=4.04)$, parity more than two times $(\mathrm{OR}=2.89)$ and history of birth control pills consumption more than 10 years $(O R=6.52)$ were the independent factors that were associated with the cervical cancer incidence.
\end{abstract}

Conclusions: Parity more than two times, history of birth control pills consumption more than 10 years, history of passive smoking, not knowing that cervical cancer can be prevented and never having a pap smear test were the factors associated with cervical cancer incidence.

\author{
*Corresponding author: \\ Aisyiah Rahmi Putri \\ Faculty of Medicine, Airlangga \\ University, Surabaya, Indonesia. \\ aisyiahrp169@gmail.com
}

cervical cancer if not handled properly [3]. Vaccination of HPV, screening, and treatment of precancerous lesions are the prevention of cervical cancer [4].

Several studies have been conducted to determine the risk factors for cervical cancer. The risk factors studied include the age of the first sexual intercourse $[2,5-7]$, the number of sexual partners [8], parity [9-11], oral contraceptive use [12-15], and the long-term smoking [6,16-18], but these studies show mixed results.

This study examined the association of risk factors of parity, history birth control pills consumption and smoking with cervical cancer in new cervical cancer patients in The Gynecologic-Oncology Clinic of Dr. Soetomo Hospital Surabaya from March 2016 to August 2016. This study also recorded the patients' knowledge of cervical cancer preventions, history of HPV vaccination 
and pap smear screening test to determine whether the risk factors of cervical cancer are well known by the patients and whether the patients know if HPV vaccination and pap smear test can be done to prevent the incidence of the cervical cancer.

\section{METHODS}

\section{Participant}

The case-control study was conducted to investigate if the risk factors are associated with cervical cancer. The population in this study was divided into case and control populations. The case population is the new cervical cancer patients in The Gynecologic-Oncology Clinic of Dr. Soetomo Hospital Surabaya from March 2016 to August 2016. The control population is the patients who visited the Obstetrics and Gynecology Clinic of Dr. Soetomo Hospital and were not diagnosed with cervical cancer. The inclusion criteria of this study were patients diagnosed with cervical cancer and consented to participate in this study. The respondents that did not answer the questionnaires completely were excluded from this study. The sample size was calculated using the Hosmer-Lemeshow formula based on the prevalence of cervical cancer patients in Indonesia in $2013(p=0.8)$ with standard error values $(\mathrm{d}=0.1)$. The minimum number of samples are 60 cases and 60 controls (1:1). The data was collected based on consecutive sampling method by taking all the data that meet the inclusion criteria. The ethical clearance for this study was issued by the Ethical Committee on Health Research of RSUD Dr. Soetomo Surabaya with registration number 68/Panke. KKE/II/2016.

\section{Statistical Analysis}

The data were obtained from the questionnaires filled out by the participants. The collected data included age, parity, history of contraception, history of HPV vaccination, history of pap smear test and knowledge about cervical cancer prevention. Due to the process of editing, coding, and tabulating, the collected data were then stratified by study variables: parity, history of birth control pills consumption and history of smoking. The data was then analyzed with IBM SPSS Statistics 23 by bivariate and multivariate logistic regression to determine the association between the risk factors and the occurrence of cervical cancer. Multivariate logistic regression analysis was performed to determine the associations among multiple independent variables to the dependent variable at the same time. To make the multivariate analysis model, bivariate analysis was first performed between each independent variable and the dependent variable to determine the $p$-value and the odds ratio (OR). The selected independent variable included in the multivariate analysis is the variable that has $p$-value less than 0.25 . The selected independent variables were then tested with the cofounder test by looking the OR difference before and after the independent variable was excluded. If the OR difference was more than $10 \%$, the excluded variable was then reentered to the cofounder test until the final multivariate model was obtained.

\section{RESULTS}

From 60 cervical cancer patients (Table 1), 1 patient (1.7\%) aged $21-30$ years, 7 patients (11.7\%) aged 31-40 years, 24 patients (40\%) aged $41-50$ years, 21 patients (35\%) aged $51-60$ years and 7 patients (11.7\%) aged more than 60 years old. The mode was 51 years old and the mean age was 48 years old. The number of patients diagnosed with the cervical cancer stage IB were 2 patients (3.3\%), stage IIB were 19 patients (31.7\%), stage IIIA was 1 patient (1.7\%), stage IIIB were 36 patients (60\%) and stage IVB were 2 patients (3.3\%).

Table 1. Distribution of cervical cancer patients

\begin{tabular}{lcr}
\hline \multicolumn{1}{c}{ Characteristics } & $\begin{array}{c}\text { Frequency } \\
(\mathbf{n}=60)\end{array}$ & $\begin{array}{c}\text { Percent } \\
\text { (\%) }\end{array}$ \\
\hline Age (years old) & & \\
$21-30$ & 1 & 1.7 \\
$31-40$ & 7 & 11.7 \\
$41-50$ & 24 & 40 \\
$51-60$ & 21 & 35 \\
$>60$ & 7 & 11.7 \\
\hline Cervical cancer stage & & \\
IB & 2 & 3.3 \\
IIB & 19 & 31.7 \\
IIIA & 1 & 1.7 \\
IIIB & 36 & 60 \\
IVB & 2 & 3.3 \\
\hline
\end{tabular}

The bivariate logistic regression analysis confirmed that parity more than two times $(p=0.001)$, history of birth control pills consumption more than 10 years $(p=0.04)$, passive smoking $(p=0.001)$ and knowledge of cervical cancer prevention $(p=0.001)$ were significantly associated to the incidence of cervical cancer (Table 2 ). 
Table 2. Bivariate analysis of risk factors for cervical cancer

\begin{tabular}{|c|c|c|c|c|c|c|}
\hline \multirow{3}{*}{ Variables } & \multicolumn{4}{|c|}{ Diagnosis } & \multirow{3}{*}{ p-value } & \multirow{3}{*}{ OR $(95 \% \mathrm{Cl})$} \\
\hline & \multicolumn{2}{|c|}{ Cervical cancer } & \multicolumn{2}{|c|}{ Non-cervical cancer } & & \\
\hline & $\mathbf{n}$ & $\%$ & $\mathbf{n}$ & $\%$ & & \\
\hline \multicolumn{7}{|l|}{ Parity } \\
\hline Never or $\leq 2$ times & 25 & 41.7 & 43 & 71.6 & \multirow{2}{*}{$0.001^{*}$} & \multirow{2}{*}{$3.54(1.66-7.58)$} \\
\hline$>2$ times & 35 & 58.3 & 17 & 28.3 & & \\
\hline \multicolumn{7}{|c|}{ Birth control pills consumption } \\
\hline Never or $\leq 10$ years & 52 & 86.7 & 59 & 98.3 & \multirow{2}{*}{$0.04^{*}$} & \multirow{2}{*}{$9.08(1.09-75.02)$} \\
\hline$>10$ years & 8 & 13.3 & 1 & 1.7 & & \\
\hline \multicolumn{7}{|l|}{ History of smoking } \\
\hline Non-smoker & 9 & 15 & 27 & 45 & \multirow[t]{2}{*}{$0.001^{*}$} & \multirow[t]{2}{*}{4.64 (1.94-11.09) } \\
\hline Passive smoker & 51 & 85 & 33 & 55 & & \\
\hline \multicolumn{7}{|c|}{ Knowledge of cervical cancer prevention } \\
\hline Know & 6 & 10 & 29 & 48.3 & \multirow[b]{2}{*}{$0.001^{*}$} & \multirow[b]{2}{*}{$8.42(3.15-22.52)$} \\
\hline Do not know & 54 & 90 & 31 & 51.7 & & \\
\hline \multicolumn{7}{|l|}{ History of HPV Vaccination } \\
\hline Yes & 0 & 0 & 1 & 1.7 & \multirow[t]{2}{*}{1} & \\
\hline Never & 60 & 100 & 59 & 98.3 & & - \\
\hline \multicolumn{7}{|l|}{ History of Pap Smear Test } \\
\hline$>1$ time & 4 & 6.7 & 6 & 10 & \multirow[t]{2}{*}{0.512} & \multirow[t]{2}{*}{$1.56(0.42-5.82)$} \\
\hline Never or only 1 time & 56 & 93.3 & 54 & 90 & & \\
\hline
\end{tabular}

OR, odds ratio; $\mathrm{Cl}$, confidence interval

*Significant

The multivariate logistic regression analysis confirmed that not knowing that cervical cancer can be prevented, the history of passive smoking, parity more than two times and history of birth control pills consumption more than 10 years were the independent factors that are associated with the incidence of cervical cancer (Table 3).

Table 3. The final model of the multivariate logistic regression analysis

\begin{tabular}{lcc}
\hline Variables & p-value & OR (95\% Cl) \\
\cline { 1 - 2 } $\begin{array}{l}\text { Knowledge of cervical } \\
\text { cancer prevention }\end{array}$ & 0.001 & $6.85(2.39-19.59)$ \\
$\begin{array}{l}\text { History of smoking } \\
\text { Parity }\end{array}$ & 0.006 & $4.04(1.49-10.91)$ \\
$\begin{array}{l}\text { Birth control pills } \\
\text { consumption }\end{array}$ & 0.020 & $2.89(1.18-7.10)$ \\
\hline
\end{tabular}

\section{DISCUSSION}

The onset of cervical cancer in the new cervical cancer patients in The Gynecologic-Oncology Clinic of Dr. Soetomo Hospital Surabaya from March 2016 to August 2016 was at the age of 21-30 years with rapid increase between the age of 40 and 60 years. These results show similarities with the data from International
Agency for Research on Cancer (IARC) [19], that the onset of cervical cancer in Denmark, Germany, Netherlands, Norway, Slovenia, and Sweden was at the age of 25 years with the rapid increase between the age of 30 and 40 years and the peak was at the age of 44-49 years and declined after that age. In America, Asia, Africa, Finland and Poland, the onset of cervical cancer incidence also occurred between the ages of 30 and 40 years, but the peak occurred in older ages, i.e. 50-65 years, and declined after that age.

A study by Autier et al. [11] showed that the transformation zone was located on the ectocervix in $94 \%$ of women younger than 25 years old. As age increased, the proportion of women with a transformation zone located on the ectocervix steadily decreased to reach less than $2 \%$ after 64 years old. As compared with women having a transformation zone in the endocervical canal, the age-adjusted likelihood of discovering a histologically proven dysplastic lesion was 1.8 times more frequent among women with a transformation zone located on the ectocervix $(95 \%$ confidence interval 1.1-2.9).

From 60 new cervical patients in the GynecologicOncology Clinic of Dr. Soetomo Hospital Surabaya from March 2016 to August 2016, 60\% of them were diagnosed with stage III B cervical cancer. This could be due to the low awareness about reproductive health and the lack of knowledge about the symptoms of cervical cancer. It is necessary to arrange a program 
for improving the knowledge about reproductive health and the symptoms of cervical cancer.

The new cervical cancer patients in the GynecologicOncology Clinic of Dr. Soetomo Hospital Surabaya from March 2016 to August 2016 that had given birth more than twice had a higher risk of cervical cancer than the patients that have never given birth. These results show similarities with the results of the study conducted by Munoz et al. [9] in 2002, women that had given birth more than 7 times had a higher risk $(O R=3.8)$ of squamous cell carcinoma (SCC) type of cervical cancer than women that have never given birth. The OR of cervical cancer in women that had given birth of 3-6 children was 2.6-2.8 and in women that had given birth more than 7 times was 3.8. The exact cause of the increased risk of cervical cancer with multiparity is still unknown. A theory says that hormonal changes during pregnancy make it easier for pregnant women to be infected with HPV and develop cancers. Another theory says that during pregnancy the immune system decreases that makes it easier for pregnant women to be infected with HPV [10]. Furthermore, it has been shown that the transformation zone remains on the ectocervix for longer in multiparous women and thereby facilitates direct exposure to HPV and potential cofactors. Local tissue damage during vaginal delivery or cellular oxidative stress with increased likelihood of DNA damage and HPV integration may be possible mechanisms [11].

The birth control pill contains a combination of estrogen and progesterone or progesterone only [12]. HPV-16 GRE showed a response to progesterone [13]. High levels of sex hormones appear to be involved in cervical carcinogenesis, estrogen has been suggested to stimulate HPV gene expression, influence the cervical immune response, and stimulate cell proliferation in the transformation zone [14]. In this study, the consumption of birth control pills shows a significant association with the incidence of cervical cancer. A study by Moreno et al. [14] in 2002 showed that the use of oral contraceptives for 5-9 years had higher risk for cervical cancer with OR of 2.82 (95\%) Cl 1.46-5.42 and the $O R$ for the use of oral contraceptives for 10 years or longer was 4.03 (2.09-8.02), and these risks did not vary by time since first or last use.

This study has found approximately $85 \%$ of the new cervical cancer patients in the Gynecologic-Oncology Clinic of Dr. Soetomo Hospital Surabaya from March 2016 to August 2016 were passive smokers and had a higher risk of cervical cancer than "non-smoker" patients. A study conducted by Burk et al. [6] in 1996 showed that women who lived with a smoker had a higher risk of developing cervical cancer $(O R=1.9)$. A study conducted by Hellberg et al. [16] in 1988 showed that cotinine and nicotine were shown to be strongly concentrated in cervical mucus compared with serum levels and could be carcinogenic to the cervical epithelial cells. Tobacco smoking was suspected reducing the Langerhans cells and CD4 lymphocytes [17]. The in vivo effects of long-term nicotine exposure could affect persistent cellular proliferation, inhibition of apoptosis, and stimulation of vascular endothelial growth factor with increased microvessel density. Other mechanisms that may explain smoking-related carcinogenesis are related to abnormalities in the systemic and peripheral immune systems of smokers that include unbalanced systemic production of pro- and anti-inflammatory cytokines [18].

According to the American Cancer Society, most cervical cancers are found in women who have never had a pap smear test or who have not had one recently [20]. In this study, 93.3\% of cervical cancer patients never had a pap smear test or only had the pap smear test for one time. However, the history of pap smear test was not significantly associated with the incidence of cervical cancer $(p=0.512), 90 \%$ of "non-cervical cancer" patients also never had a pap smear test or only had the pap smear test for one time.

In this study, HPV vaccination was not significantly associated with the incidence of cervical cancer. Only $1.7 \%$ "non-cervical cancer" patients got the HPV vaccination and $100 \%$ of cervical cancer patients never get HPV vaccination. However, a study on the cervical cancer knowledge, prevention and exposure to risk factors among students from various countries conducted by Romejko-Wolniewicz [21] showed that countries with lower cervical cancer incidence and mortality had higher rate of performed pap smears, HPV tests, and HPV vaccinations and had higher awareness of cervical cancer risk factors. In this study, the bivariate and multivariate logistic regression analysis confirmed that not knowing cervical cancer could be prevented was significantly associated with the incidence of cervical cancer. The percentage of patients that did not know if cervical cancer could be prevented was higher in both cervical cancer and non-cervical cancer patients. However, in non-cervical cancer patients, $48.3 \%$ knew that cervical cancer could be prevented, in comparison, only $10 \%$ of cervical cancer patients knew that cervical cancer could be prevented. A study conducted by Adeyemi et al. [22] showed that the knowledge of women in Nigerian tertiary hospitals regarding cervical cancer symptoms was poor (40\%) and the knowledge regarding risk factors of cervical cancer was very poor (15.6\%). The uptake of the pap smear test was also very low $(22.9 \%)$, the major reasons for not having a pap smear were lack of awareness (53.8\%), while the major reasons for having a pap smear were recommendation from doctors/nurses (89.4\%). From these results, despite the evidence of methods for cervical cancer prevention, such as pap smear test and HPV vaccination, most of the women never get HPV vaccination and remain unscreened because of the lack of awareness and the 
low knowledge about the cervical cancer preventions. Due to low knowledge regarding cervical cancer risk factors and symptoms, most cervical cancer cases are not diagnosed early enough leading to poor outcomes.

This study had data limitations. The data were collected with the questionnaires filled out by 60 newly diagnosed cervical cancer patients and 60 non-cervical cancer patients at the Gynecologic-Oncology Clinic of Dr. Soetomo Hospital Surabaya in the period of March 2016 until August 2016. The questionnaire answers filled out by the respondents were subjective. There could be differences in perceptions between the researchers and respondents. The quality of the data depended on the recall and the honesty of the respondents. There were possibilities that the respondents' answers were not in accordance with the actual conditions.

\section{CONCLUSIONS}

Parity more than two times, birth control pills consumption more than 10 years, passive smoking, and not knowing that cervical cancer can be prevented were associated with a higher risk of cervical cancer incidence in new patients at the Gynecologic-Oncology Clinic of Dr. Soetomo Hospital Surabaya from March 2016 to August 2016.

Based on these results, it is necessary to arrange a program for improving the knowledge about reproductive health, symptoms of cervical cancer and the importance of HPV vaccination and early screening test for preventing the incidence of cervical cancer. With this approach, it is expected that the incidence of cervical cancer can be reduced.

\section{DECLARATIONS}

\section{Competing of Interest}

There is no conflict of interest in this study.

\section{Acknowledgement}

This research was supported by the Community Medicine Department of Medicine Faculty of Airlangga University Surabaya, the Obstetric and Gynecologic Department Dr. Soetomo Hospital Surabaya and the GynecologicOncology Clinic Dr. Soetomo Hospital Surabaya.

\section{REFERENCES}

1. Kementrian Kesehatan Republik Indonesia. Situasi penyakit kanker. http://www.depkes.go.id/resources/ download/pusdatin/infodatin/infodatin-kanker.pdf (accessed August 22, 2015).

2. Rasjidi I. Deteksi dini, dan pencegahan kanker pada wanita. Jakarta: CV Sagung Seto;2009.

3. Chung SH, Franceschi S, dan Lambert PF. Estrogen and ERa: culprits in cervical cancer. Trends Endocrinol Metab. 2010;21(8):504-11.

4. World Health Organization. Comprehensive cervical cancer prevention and control: a healthier future for girls and women. http://apps.who.int/iris/bitstr eam/10665/78128/3/9789241505147_eng.pdf?ua=1 (accessed January 14, 2017).

5. Louie KS, Sanjose S de, Diaz M, Castellsague, Herrero R, Meijer CJ, Shah K, Franceshi S, Munoz N, Bosch FX. Early age at first sexual intercourse and early pregnancy are risk factors for cervical cancer in developing countries. Br J Cancer. 2009;100:1191-7.

6. Burk R, Ho G, Beardsley L, Lempa $M$, Peters $M$, Bierman R. Sexual behavior and partner characteristics are the predominant risk factors for genital human papillomavirus infection in young women. J Infect Dis. 1996;174(4):679-89.

7. Boardman $\mathrm{CH}$, Sonoda Y. Cervical Cancer Staging. http://emedicine.medscape.com/article/2006486overview (accessed August 22, 2015).

8. Liu ZC, Liu WD, Liu YH, Ye XH, Chen SD. Multiple Sexual Partners as an independent risk factor for cervical cancer: a meta-analysis of epidemiological studies. Asian Pac J Cancer Prev. 2015;16(9):3893-3900.

9. Munoz N, Franceschi S, Bosetti C, Moreno V, Herrero R, Smith J, Shah K, Meijer C, Bosch X. Role of parity and human papillomavirus in cervical cancer: the IARC multicentric case-control study. The Lancet. 2002;359(9312):1093-1101.

10. Saslow D, Solomon D, Lawson HW, Killackey M, Kulasingam S, Cain J, Garcia F, et al. American Cancer Society, American Society for Colposcopy and Cervical Pathology, and American Society for Clinical Pathology screening guidelines for the prevention and early detection of cervical cancer. J Low Genit Tract Dis. 2012;16(3):175-204.

11. Autier P, Coibion M, Huet F, Grivegnee AR. Transformation zone location and intraepithelial neoplasia of the cervix uteri. $\mathrm{Br} J$ Cancer. 1996;74(3):488-90.

12. BKKBN. Pil KB. http://www.bkkbn-jatim.go.id/bkkbnjatim/html/pil.htm (accessed August 22, 2015). 
13. Chan WK, Klock G, Bernard HU. Progesterone and glucocorticoid response elements occur in the long control regions of several human papillomaviruses involved in anogenital neoplasia. J Virol. 1989;63(8):3261-9.

14. Moreno V, Bosch FX, Munoz N, Meijer CJ, Shah KV, Walboomers JM, Herrero R, Franceschi S. Effect of oral contraceptives on risk of cervical cancer in women with human papillomavirus infection: The IARC multicentric case-control study. Lancet 2002;359(9312):1085-92.

15. Syrjanen K, Shabalova I, Petrovichev N, Kozachenko V, Zakharova T, Pajanidi J, Podistov J, et al. Oral contraceptives are not an independent risk factor for cervical intraepithelial neoplasia or high-risk human papillomavirus infections. Anticancer Res. 2006;26(6C):4729-40.

16. Hellberg D, Nilsson S, Haley NJ, Hoffman D, Wynder E. Smoking and cervical intraepithelial neoplasia: nicotine and cotinine in serum and cervical mucus in smokers and nonsmokers. Am J Obstet Gynecol. 1988;158(4):910-3.

17. Vaccarella $S$, Herrero R, Snijders $P$, Dai M, Thomas J, Hieu NT, Ferreccio C, et al. Smoking and human papillomavirus infection: Pooled analysis of the International Agency for Research on Cancer HPV Prevalence Surveys. Int J Epidemiol. 2008;37(3):536-46.

18. Alberto J, Moutinho F. Smoking and cervical cancer. ISRN Obstet Gynecol. 2011;847684.
19. International Agency for Research on Cancer. IARC handbook of cancer prevention http://www.iarc.fr/ en/publications/pdfs-online/prev/handbook10/ HANDBOOK10.pdf (accessed January 7, 2017).

20. American Cancer Society. The American cancer society guidelines for the prevention and early detection of cervical cancer. https://www.cancer.org/ cancer/cervical-cancer/prevention-and-earlydetection/cervical-cancer-screening-guidelines.html (accessed August 19, 2019).

21. Romejko-Wolniewicz, E. Cervical cancer knowledge, prevention and exposure to risk factors among students from various countries. Medical University of Warsaw, Department of Obstetrics and Gynaecology Warsaw, Poland. IFCPC 2017 World Congress. http:// www.asccp.org/Assets/d3474b4c-ccb9-4e7a-8db3215ff70933d9/636281254732730000/x-worldcongress-17-presentation-ewa-romejko-wolniewicz-1pptx-pdf. (accessed September 9, 2019).

22. Adeyemi O, Daramola E, Adaiah S, Francis E, Jubril $\mathrm{K}$, Kehinde $\mathrm{O}$, Rose A. Women's knowledge of cervical cancer and uptake of Pap smear testing and the factors influencing it in a Nigerian tertiary hospital. JCRP. 2018;5(3):105-11. 